\title{
A INTERAÇÃO DO VENTO LOCAL NO INTERIOR DE UM VALE COM O ESCOAMENTO DE GRANDE ESCALA - ANÁLISE DE DOIS ESTUDOS DE CASO
}

\author{
DANIEL PIRES BITENCOURT ${ }^{1}$; OTÁVIO COSTA ACEVEDO ${ }^{2}$; \\ OSVALDO LUIZ LEAL DE MORAES ${ }^{2}$ E GERVÁSIO ANNES DEGRAZIA ${ }^{2}$ \\ ${ }^{1}$ Fundação Jorge Duprat Figueiredo de Segurança e Medicina do Trabalho \\ (FUNDACENTRO), Florianópolis, SC \\ ${ }^{2}$ Universidade Federal de Santa Maria (UFSM), Santa Maria, RS \\ daniel@fundacentro.sc.gov.br, otavio@smail.ufsm.br, \\ moraes@ccne.ufsm.br, degrazia@ccne.ufsm.br
}

Recebido Março 2008 - Aceito Junho 2009

\begin{abstract}
RESUMO
Este artigo apresenta dois estudos de caso com objetivo de investigar a interação do vento local no interior de um vale, com o vento sinótico. A direção e a velocidade do vento local são obtidas de dados de resposta lenta medidos em um trecho leste/oeste do vale do rio da Prata, localizado na região de Nova Roma do Sul, Estado do Rio Grande do Sul. Os dados sinóticos da direção e velocidade dos ventos foram observados às 00,12 e 18 TMG, em três estações meteorológicas de superfície localizadas na mesorregião do vale estudado. O padrão sinótico é avaliado através de campos meteorológicos construídos com a reanálise do NCEP-NCAR. A análise sinótica e a avaliação empírica do vento local são realizadas com a ajuda de outras variáveis medidas no fundo do vale, tais como radiação solar incidente e temperatura do ar. Os resultados mostram a existência de superposição das forçantes, térmica e canalizada, durante a madrugada e parte da manhã. Porém, quando a temperatura do ar durante a madrugada é baixa, o efeito térmico parece ser mais pronunciado do que o efeito do vento sinótico canalizado. O vento sinótico de norte proporciona um padrão característico do vento local no interior do vale. $\mathrm{O}$ escoamento vale abaixo é relativamente mais forte entre a madrugada e a manhã devido à soma dos efeitos, térmico e canalizado. Por outro lado, esses efeitos anulam-se a partir das 12 - $13 \mathrm{~h}$, provocando calmaria no interior do vale.
\end{abstract}

Palavras-Chaves: vale; vento sinótico; vento local

ABSTRACT: INTERACTION OF THE LOCAL WIND WITHIN A VALLEY WITH THE LARGESCALE FLOW - ANALYSIS OF TWO CASE STUDIES

This paper shows two case studies to investigate the interaction of the local wind within a valley with the synoptic-scale wind. The direction and velocity of the local wind are obtained from slow response data measured within an east/west section of Prata valley in Nova Roma do Sul, Rio Grande do Sul State, Brazil. The synoptic direction and velocity wind were observed at 00, 12 and 18 TMG at three meteorological surface stations, situated in the studied valley. The synoptic pattern is evaluated by the NCEP-NCAR reanalysis of meteorological fields. The synoptic analysis and empirical evaluation of local wind are done with the use of others variables in the bottom of the valley, as incident solar radiation and air temperature. The results showed that there is a superposition of the thermal and the channeled flow forcings within the valley during the first hours and part of the morning. However, when the air temperature during the early morning is low, the thermal effect seems to be more pronounced than the synoptic channeled wind effect. The down-valley wind flow is relatively stronger during the early and the late morning due to the superposition of both thermal and channeled effects. On the other hand, these effects cancel each other from 12-13 hour, causing calm winds within the valley.

Keywords: valley; synoptic-scale wind; local wind 


\section{INTRODUÇÃO}

Em meados do século passado foram feitas as primeiras pesquisas a respeito das circulações que ocorrem em um sistema de vale/montanha. Defant (1951) identificou os escoamentos clássicos que ocorrem montanha acima durante o dia, montanha abaixo durante a noite e também os escoamentos ao longo do vale, onde a circulação ocorre vale acima a partir do meio do dia e vale abaixo a partir do meio da noite, todos forçados termicamente. Posteriormente, muitos artigos científicos abordaram a estrutura da baixa atmosfera em áreas de terreno complexo, em especial no estudo da estrutura do vento e da temperatura em sistemas de vale/montanha (Whiteman, 1982; Whiteman e Mckee, 1982; Bader e Mckee, 1983; Whiteman et al., 1999; Doran e Horst, 1981). A partir da década de 80, alguns autores iniciaram investigações sobre os efeitos do escoamento de grande escala na estrutura da atmosfera do interior de vales (Cotton et al., 1982; Segal et al., 1983; Banta, 1984; Whiteman e Doran, 1993; Weigel e Rotach, 2004).

A circulação no fundo do vale do rio da Prata, localizado em Nova Roma do Sul (NRS), estado do Rio Grande do Sul (RS), exerce um importante papel nos processos de trocas de calor sensível e latente entre o rio e a atmosfera local. Bitencourt e Acevedo (2008) estudaram esses processos, utilizando dados observados e resultados de simulações numéricas, da camada limite planetária. Os autores concluíram que os ventos locais, existentes nesse vale, são função do complexo relevo da região, dos gradientes térmicos provocados pela orografia e contraste água/solo e da velocidade e direção do escoamento de grande escala. Comparações empíricas entre o escoamento de grande escala e a circulação local, utilizando a reanálise do "National Center for Environmental Prediction - National Center for Atmospheric Research" (NCEP - NCAR) e observações no fundo do vale, também apontam para existência de superposição das forçantes canalizada e térmica no interior do vale (Bitencourt e Acevedo, 2006). Essa interação de forças, provenientes de diferentes escalas, são verificadas em outras regiões de vale, como nos Estados Unidos da América (EUA) (Whiteman e Doran, 1993). Somado a isso, a circulação no interior do vale do rio da Prata apresenta características que podem estar associadas à outros processos físicos, tais como o nevoeiro. Esse fenômeno é particularmente importante para a região montanhosa de NRS. A formação do nevoeiro no solo pode ser explicada pelo resfriamento radiativo da superfície associado às trocas de calor em baixos níveis. De acordo com Pilié et al. (1975), a evaporação do orvalho depois do nascer do sol mantém a saturação em toda a camada do nevoeiro, mantendoo persistente. De acordo com Acevedo e Fitzjarrald (2001), o saldo de umidade junto a superfície é determinante para o tempo de duração do nevoeiro. Para o caso do vale do rio da Prata, além da contribuição da evaporação do orvalho na vegetação das encostas, há a contribuição da evaporação da água do rio.
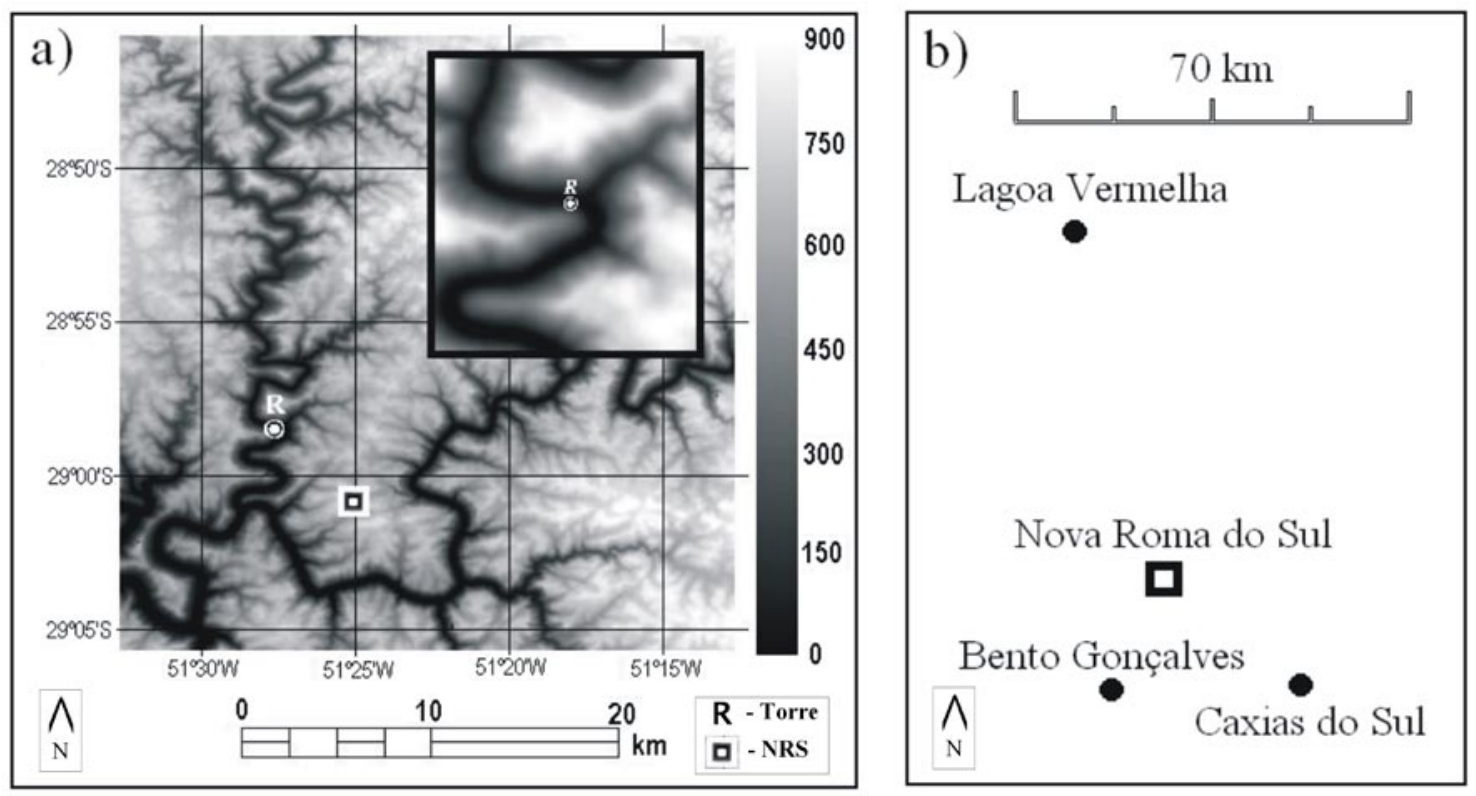

Figura 1 - (a) Mapa de relevo da região de NRS, conforme escala (metros) de cinza mostrada na legenda da direita. O detalhe do trecho do vale do rio da Prata é mostrado no canto superior direito. (b) Distribuição espacial das três estações meteorológicas do INMET em relação ao município de NRS.

Adaptado de Acevedo et al. (2005) 
Os nevoeiros que se formam nessa região caracterizam-se pela freqüência quase diária do fenômeno e pela longa duração do mesmo. Durante a campanha EXPANTAS (Experimento de Observações das Transferências entre a Superfície e a Atmosfera na Região do Rio das Antas) isso foi observado pelo sinal de radiação de onda curta incidente, que mostrava uma abrupta transição no meio da manhã, quando da dissipação do nevoeiro (Acevedo et al., 2007). Segundo Fitzjarrald e Lala (1989), que estudaram 14 casos de nevoeiros de radiação no vale do rio Hudson, em Nova York, os nevoeiros que persistem por mais de $\sim 30$ minutos, freqüentemente apresentam espessura maior que $50 \mathrm{~m}$. As medidas da radiação de onda curta incidente e as observações visuais realizadas durante a campanha EXPANTAS
- 2005 apontam para a ocorrência de nevoeiros com persistência e espessura semelhantes as encontradas por Fitzjarrald e Lala (1989). A dissipação do fenômeno ocorre quando a taxa de evaporação não é suficiente para manter a saturação. Acevedo et al. (2007) sugeriram que a dissipação do nevoeiro na região de NRS, incluindo o vale do rio da Prata, ocorre de forma heterogênea ao longo do vale. Como a direção das encostas do vale do rio da Prata é muito variável ao longo do curso do rio, a radiação solar incide com maior intensidade pela manhã nas encostas do lado oeste, nos trechos em que o vale possui a direção norte/sul. Assim, o aquecimento diferencial ao longo do vale proporcionaria a dissipação do nevoeiro primeiramente nos trechos norte/sul, favorecendo um aquecimento mais rápido
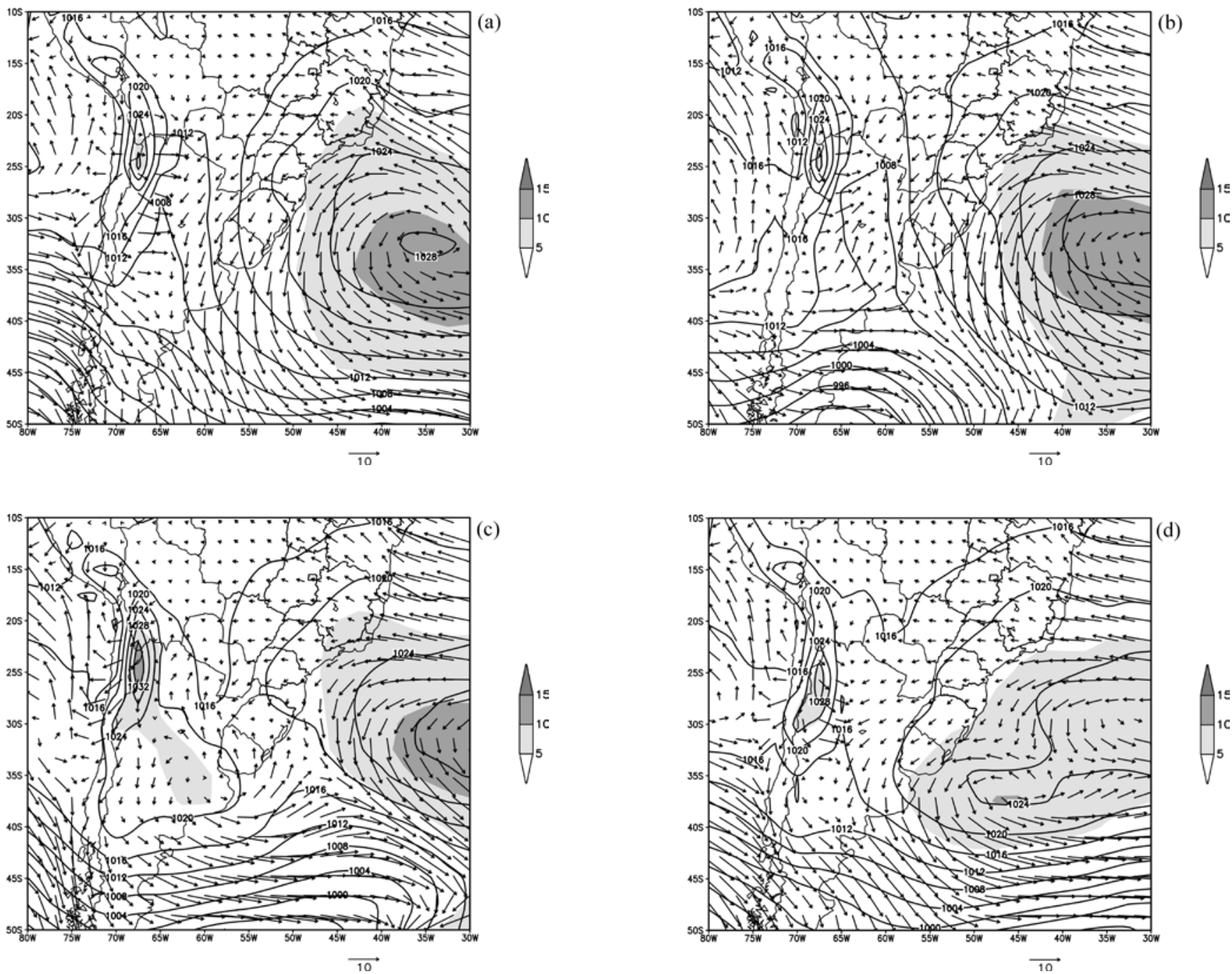

Figura 2 - Média diária da PNMM (isolinhas) e V (vetores) para os dias (a) 28, (b) 29, (c) 30 e (d) 31 de maio de 2005. A unidade da pressão é hPa e a escala dos vetores é mostrada abaixo de cada painel, em $\mathrm{m} \mathrm{s}^{-1}$. As áreas em tons de cinza mostram as anomalias positivas da PNMM, conforme legenda à direita. 
e o desenvolvimento de uma camada limite convectiva nesses locais. Ainda segundo Acevedo et al. (2007), essa situação favorece que o vento local, tipicamente de oeste (vale abaixo), transporte massas de ar com diferentes características ao longo do vale do rio da Prata.

O presente trabalho tem como principal objetivo identificar maiores detalhes da interação entre as escalas sinótica (escoamento de grande escala) e local (circulação no fundo do vale) através da análise de dois estudos de caso, com duração de 4 dias cada. Para tanto, faz-se uma breve análise sinótica dos dias estudados e, posteriormente, avalia-se o comportamento da direção e velocidade do vento local no interior do vale, em relação à direção e velocidade do vento sinótico observado em estações meteorológicas de superfície. Essas estações são localizadas em municípios próximos da região em estudo. A seção 2 apresenta os dados e metodologia utilizados nestes estudos de caso. A seção 3 apresenta os resultados e discussões e, por fim, na seção 4 são apresentadas as conclusões.

\section{DADOS E METODOLOGIA}

Os dados de direção e velocidade do vento observados no fundo do vale, tratados desse ponto do texto em diante como "vento local", foram medidos a cada 15 segundos (resposta lenta) por um anemômetro de copo R M Young localizado a $6 \mathrm{~m}$ acima da superfície do rio. $\mathrm{O}$ erro estimado para essas
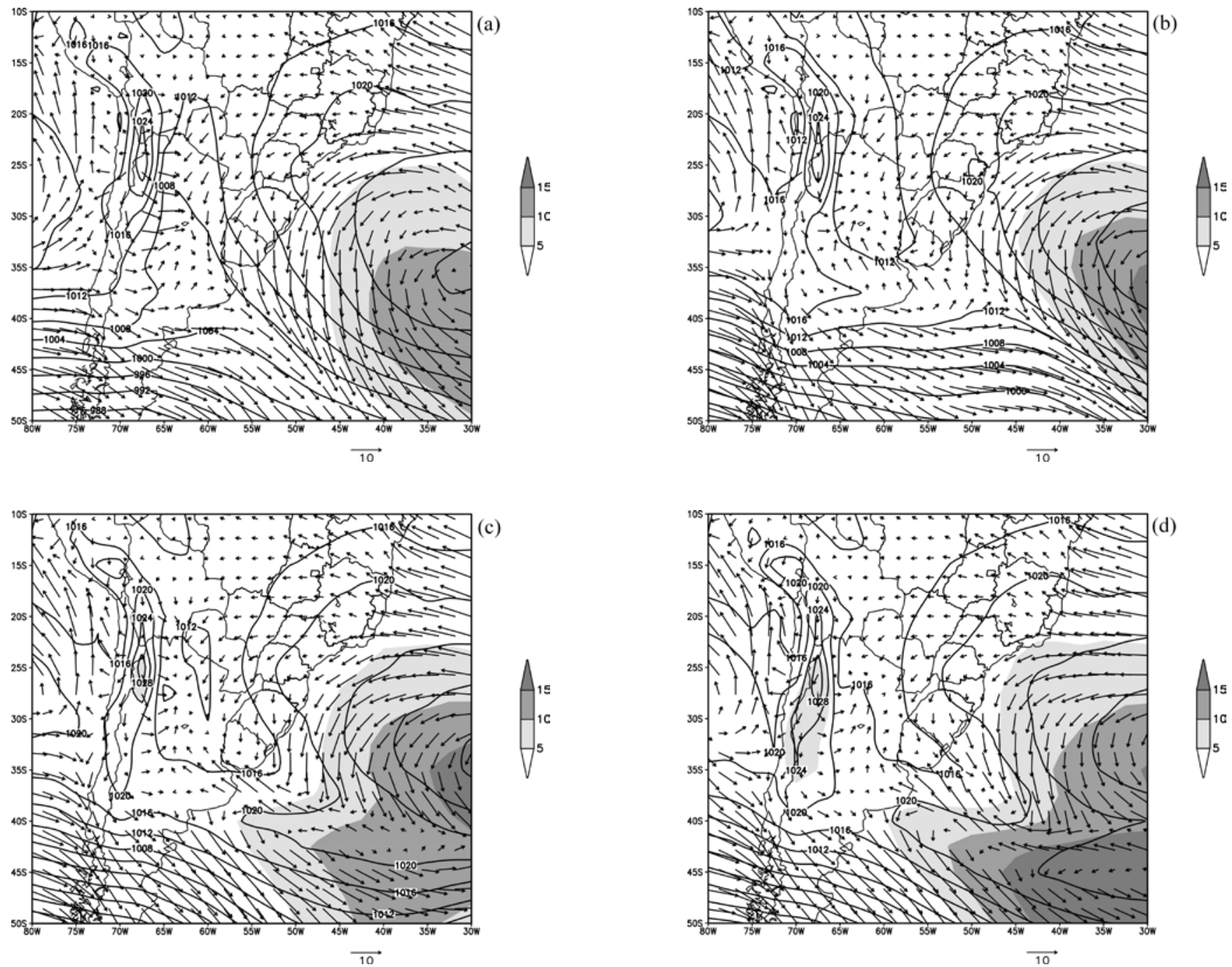

Figura 3 - Média diária da PNMM (isolinhas) e V (vetores) para os dias (a) 02, (b) 03, (c) 04 e (d) 05 de junho de 2005. A unidade da pressão é hPa e a escala dos vetores é mostrada abaixo de cada painel, em $\mathrm{m} \mathrm{s}^{-1}$. As áreas em tons de cinza mostram as anomalias positivas da PNMM, conforme legenda à direita. 
medidas é menor que $0,1 \mathrm{~ms}^{-1}$. Com intuito de filtrar movimentos turbulentos sem interesse para este estudo, a velocidade do vento local é apresentada como uma média móvel de 10 minutos. A radiação solar incidente foi observada por um radiômetro Vaisala CMP3 e a temperatura do ar por um termo-higrômetro Vaisala HMP45C, instalado na torre a $4 \mathrm{~m}$ acima da superfície do rio. Os sensores estavam instalados diretamente na torre, localizada em uma pedra, junto à margem Sul do Rio. Sensores de resposta rápida estavam instalados em uma haste metálica de $3 \mathrm{~m}$, fixada à torre por cabos de aço, de forma que ficassem
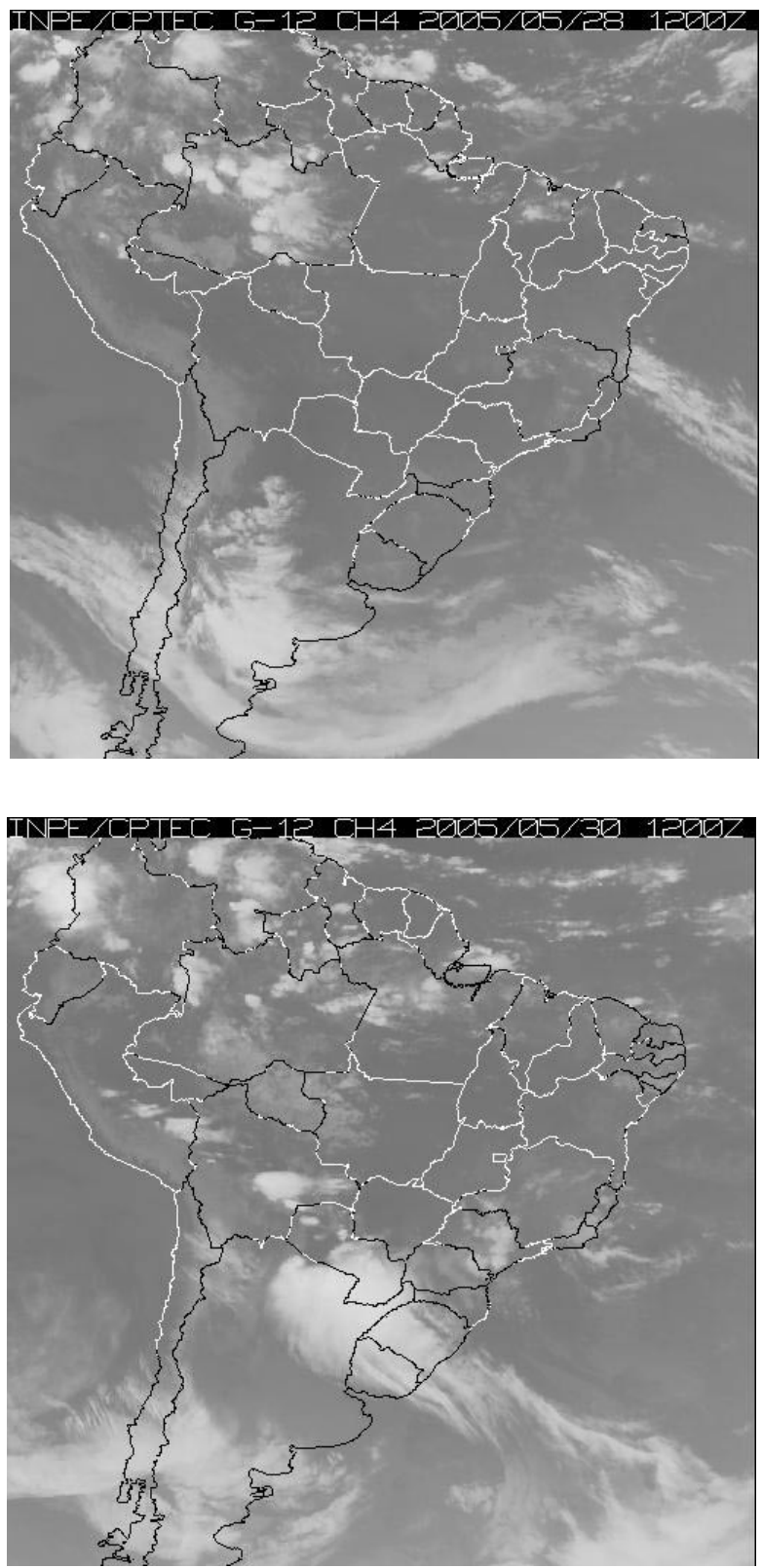

diretamente sobre a superfície do rio. Essas medidas foram realizadas em 2005 durante a campanha EXPANTAS - 2005. Os dados de fluxo são analisados de forma detalhada em Acevedo et al. (2007). A localização exata da torre micrometeorológica é indicada pela letra R na Figura 1a.

Os dados de direção e velocidade do vento, representativos do escoamento de grande escala e tratados desse ponto do texto em diante como "vento sinótico", foram observados as 0000 , 1200, 1800 TMG nas estações meteorológicas de superfície do Instituto Nacional de Meteorologia (INMET). Essas estações
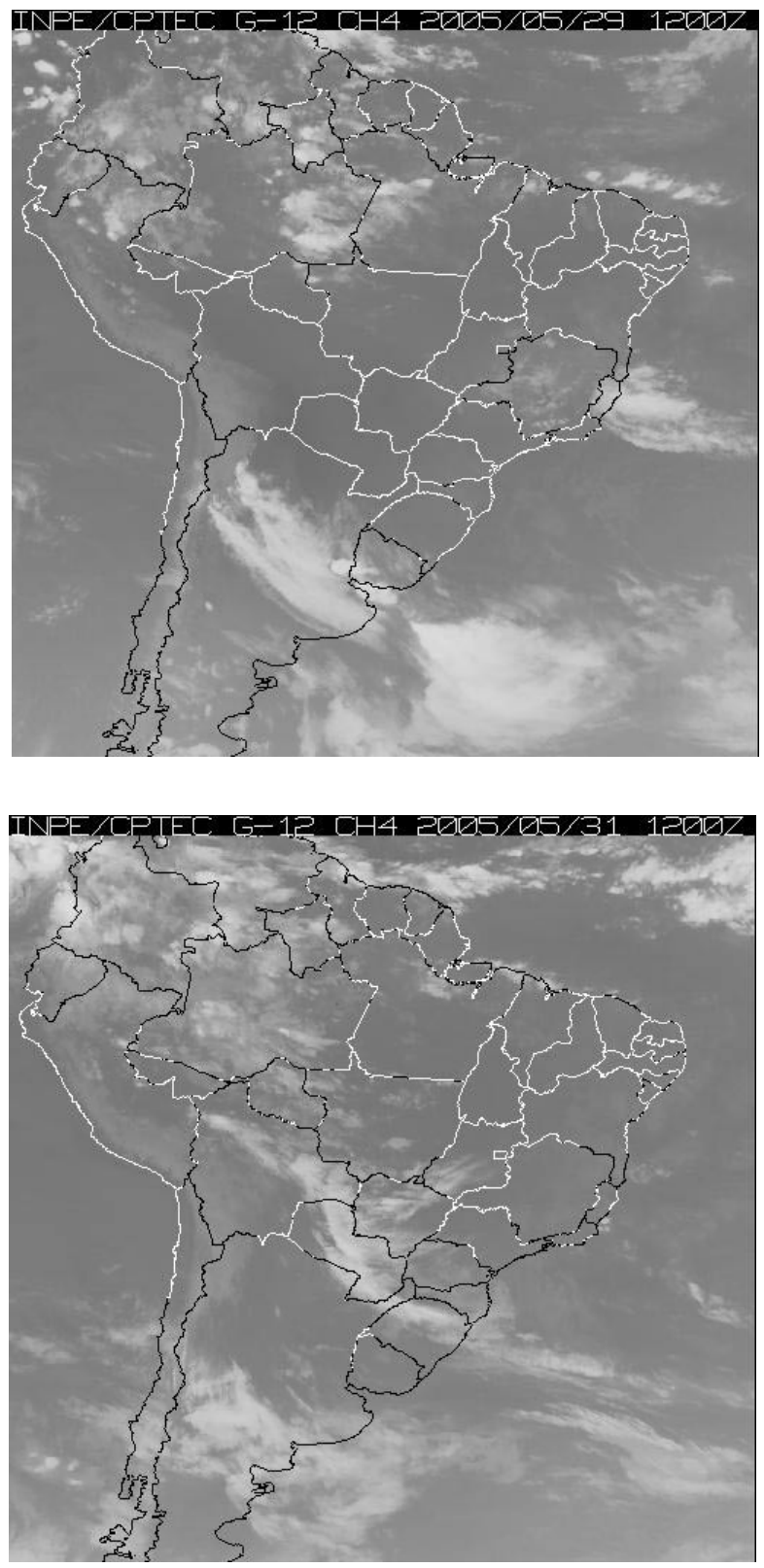

Figura 4 - Imagens do satélite geoestacionário GOES-12 no canal infravermelho das 12:00Z para os dias 28, 29, 30 e 31 de maio de 2005. Fonte: INPE/DSA 
localizam-se em Lagoa Vermelha (latitude: $28^{\circ} 25^{\prime}$; longitude: $51^{\circ} 35^{\prime}$; altitude: $805 \mathrm{~m}$ ), Bento Gonçalves (latitude: $29^{\circ} 10^{\prime}$; longitude: 51 $25^{\circ}$; altitude: $619 \mathrm{~m}$ ) e Caxias do Sul (latitude: $29^{\circ} 10^{\prime}$; longitude: $51^{\circ} 12^{\prime}$; altitude: $740 \mathrm{~m}$ ), municípios do RS que fazem parte da mesma mesorregião de NRS (Figura 1b). O município de NRS localiza-se em $29^{\circ} 01^{\prime} \mathrm{S}$ de latitude e $51^{\circ}$ $25^{\prime}$ de longitude, estando a uma altitude de $591 \mathrm{~m}$.

As condições de tempo observadas durante os dias selecionados para este estudo são analisadas através de imagens de satélite e de campos meteorológicos obtidos da reanálise do NCEP - NCAR. Essa reanálise é proveniente de dados meteorológicos de superfície em terra, navio, radiossonda, aeronaves, satélite e outros, que passaram pelo mesmo controle de qualidade e procedimento de assimilação desde 1957 (Kalnay et al., 1996). Analisam-se as médias diárias do vetor velocidade do vento (V) a $10 \mathrm{~m}$ de altura e da pressão ao nível médio do mar (PNMM). Apresenta-se também as anomalias positivas da PNMM, obtidas a partir da subtração do campo médio diário pelo campo de climatologia diária da reanálise do NCEP - NCAR. Essa climatologia foi construída a partir da série histórica de 1968 a 1996. Para identificar as contribuições térmica e canalizada dentro do vale do rio da Prata, é avaliado o comportamento do vento local em relação ao vento sinótico durante 8 dias, de 28 a 31 de maio de 2005 e de 02 a 05 de junho de 2005. Para tanto, adota-se um critério subjetivo que consiste basicamente em verificar os momentos em que a circulação no interior do vale apresenta alterações em relação ao comportamento típico proveniente da diferenciação térmica próximo à superfície. Essas alterações são avaliadas em função da temperatura observada no interior do vale (efeito local) e em função da direção e velocidade do vento, observadas nas estações meteorológicas de superfície (efeito sinótico). Além do vento e da temperatura do ar, também são analisados neste estudo de caso os dados de radiação solar incidente, medidos no fundo do vale do rio da Prata.

\section{RESULTADOS E DISCUSSÕES}

Conforme mostra a Figura 1a, a região de NRS apresenta características de terreno complexo, sendo cercada por vales altamente sinuosos. O rio da Prata corre de norte para sul e desemboca no rio das Antas, que corre de leste para oeste também no fundo de um vale. O trecho do vale do rio da Prata, onde os ventos locais utilizados nesse trabalho foram medidos
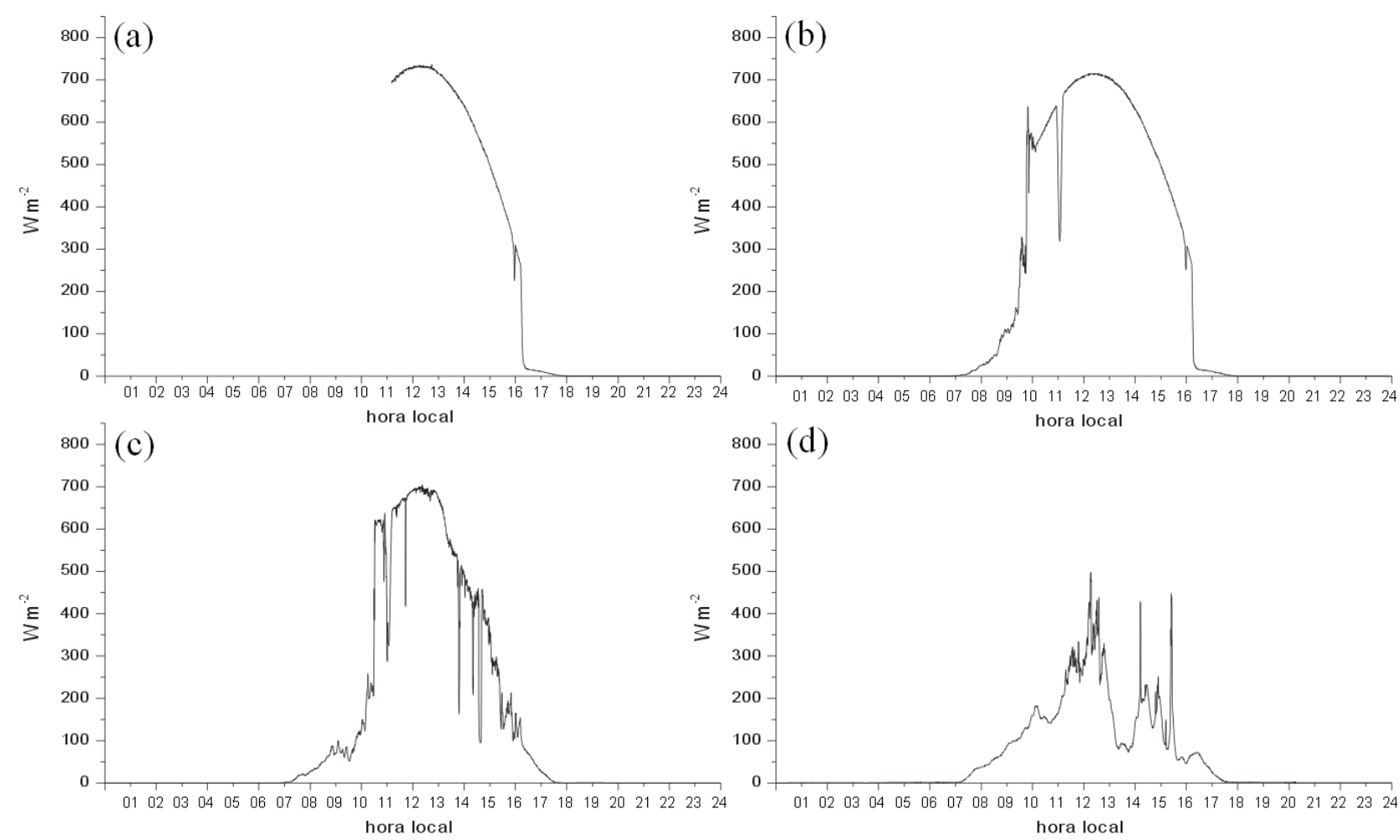

Figura 5 - Radiação solar incidente observada no vale do rio da Prata nos dias (a) 28, (b) 29, (c) 30 e (d) 31 de maio de 2005. 
(indicado por R na Figura 1a), tem orientação leste/oeste e o rio da Prata tem largura aproximada de $60 \mathrm{~m}$. As encostas apresentam altura de aproximadamente $400 \mathrm{~m}$. O detalhe, no canto superior direito da Figura 1a, mostra que o trecho de orientação norte/sul e o subseqüente trecho leste/oeste, onde as observações foram realizadas, possuem aproximadamente os mesmos comprimentos. Por outro lado, o trecho norte/sul, que faz ligação com o lado leste do trecho leste/oeste, é relativamente mais curto. De acordo com essas características, é esperado que
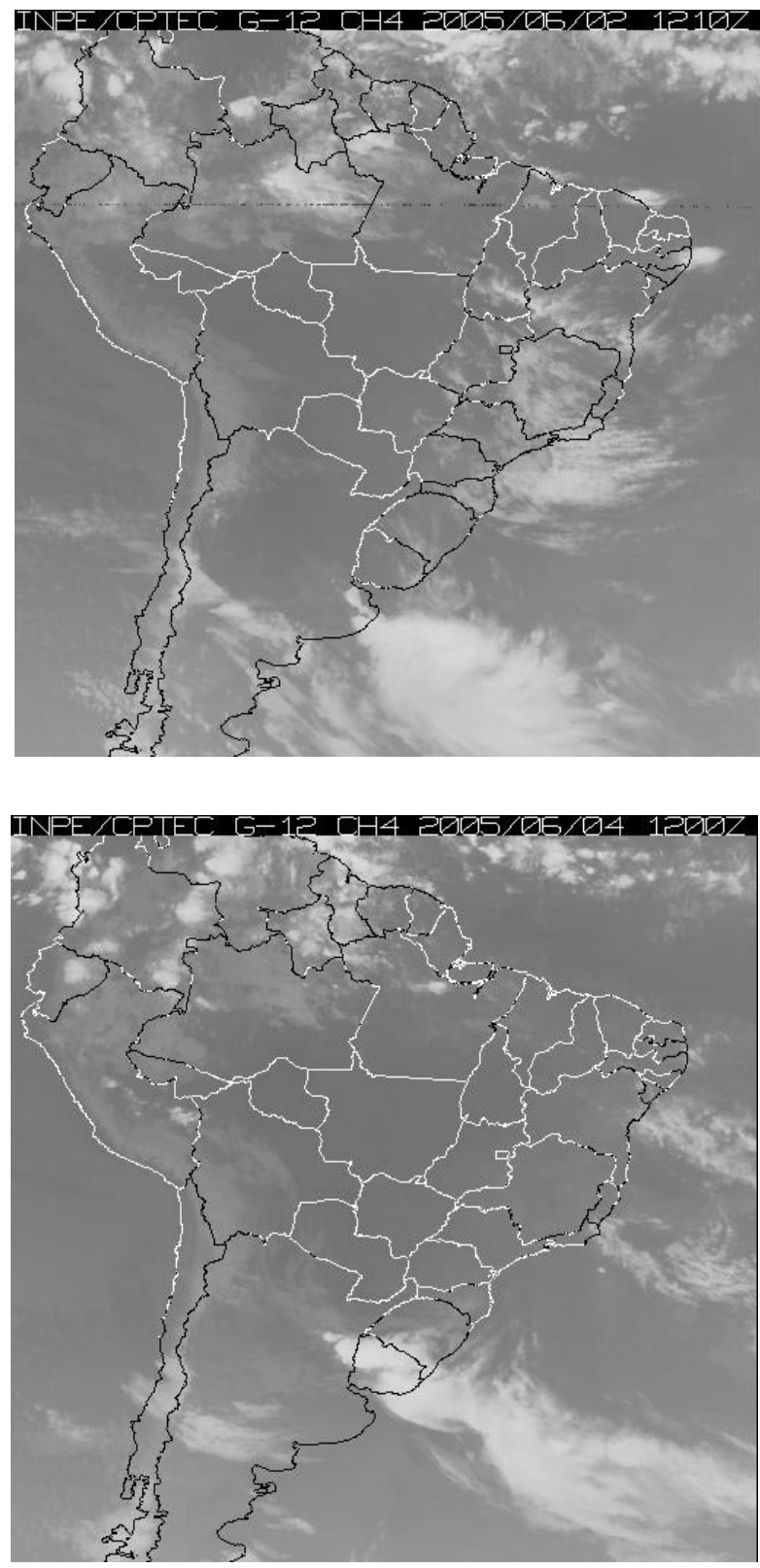

o vento local no trecho leste/oeste do vale do rio da Prata seja mais influenciado pelo vento sinótico proveniente de norte, leste ou oeste. O vento sinótico de leste ou oeste, por apresentar a mesma orientação do trecho do vale do rio da Prata em estudo, seria mais facilmente canalizado. Esse processo é similar a um dos quatro mecanismos identificados por Whiteman e Doran (1993) no vale Tennessee, nos EUA. Esses autores propõem que o vento sinótico, quando adquire a mesma orientação do vale, possibilita um forte transporte para baixo de momentum
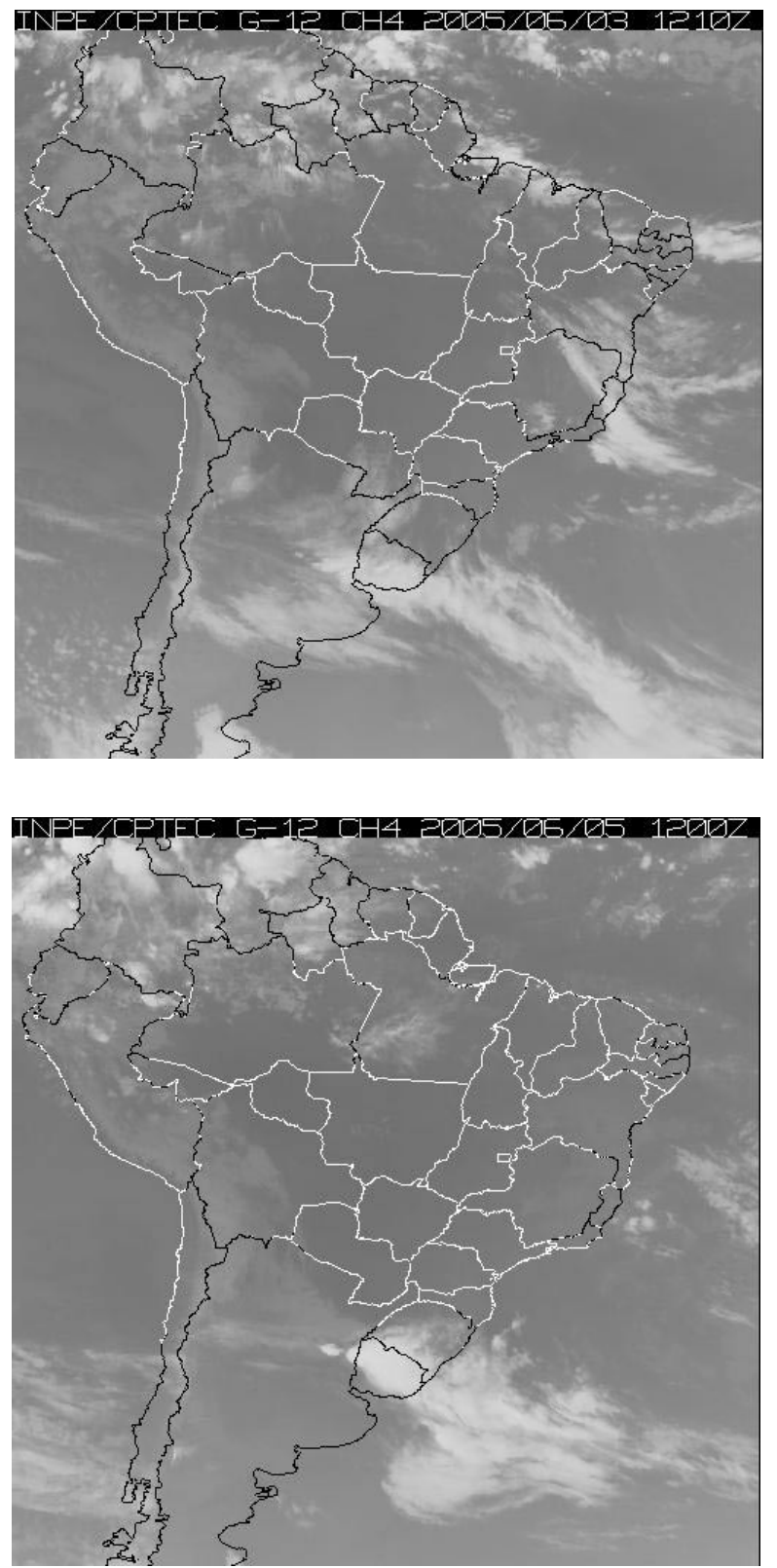

Figura 6 - Imagens do satélite geoestacionário GOES-12 no canal infravermelho das 12:00Z para os dias $02,03,04$ e 05 de junho de 2005. Fonte: INPE/DSA 
horizontal, produzindo direções do vento local no fundo do vale similares as direções do vento sinótico. $\mathrm{O}$ vento sinótico de norte, para o caso específico da microrregião em torno do ponto de observação no vale do rio da Prata, pode ser canalizado através do trecho norte/sul, que antecede o trecho leste/oeste em estudo, visto que este trecho tem extensão suficiente para ocorrer o mecanismo de transporte de momentum horizontal, conforme sugerido por Whiteman e Doran (1993). Contudo, o vento sinótico de sul não teria a mesma influência sobre o vento local no fundo do vale, dada as características de orientação já mencionadas.

Os dias escolhidos para fazer estes estudos de caso, são aqueles em que os dados de vento local foram observados sem interrupções durante todo o dia. Essas medidas foram realizadas no ano de 2005 durante a campanha EXPANTAS - 2005 (Acevedo et al., 2005). Nos dias selecionados, as condições meteorológicas de escala sinótica foram favoráveis somente para o vento do quadrante norte. As condições de tempo entre os dias 28 e 31 de maio de 2005 (Figura 2) e entre os dias 02 e 05 de junho de 2005 (Figura 3 ) foram muito semelhantes. Entre os dias 28 e 29 de maio um sistema frontal se intensificou na Argentina, avançando sobre o Uruguai e RS entre os dias 30 e 31 de maio. As imagens de satélite (Figura 4) indicam um aumento significativo de nebulosidade na região de NRS no dia 31 de maio. Os dados de radiação solar incidente, medidos no fundo do vale do rio da Prata (Figura 5), confirmam a ocorrência de maior nebulosidade para esse dia. $\mathrm{O}$ pico de radiação, por volta das $12 \mathrm{~h}$ local, foi de aproximadamente $700 \mathrm{~W} \mathrm{~m}^{-2}$ nos dias 28, 29 e 30 de maio e de aproximadamente $400 \mathrm{~W} \mathrm{~m}^{-2}$ no dia 31 de maio. Entre os dias 02 e 05 de junho, também ocorreu frontogênese entre a Argentina e o extremo sul do RS, porém a nebulosidade concentrou-se na metade sul do RS, sem atingir a região de NRS (Figura 6). O pico de radiação solar incidente medido no fundo do vale do rio da Prata foi de aproximadamente $700 \mathrm{~W} \mathrm{~m}^{-2}$ nos dias 02 e 03 de maio e de aproximadamente 600 $\mathrm{W} \mathrm{m}^{-2}$ nos dias 04 e 05 de maio (Figura 7).

Conforme mostra a reanálise do NCEP-NCAR (Figuras 2 e 3), em todos os dias desses estudos de caso, o sistema de alta pressão do Atlântico Sul esteve anomalamente mais intenso. Somado a isso, a situação de frontogênese ao sul do RS favoreceu a predominância dos ventos do quadrante norte sobre a região de NRS. Essa situação é confirmada pelos dados de direção e velocidade observados nas estações meteorológicas de superfície localizadas ao redor de NRS, conforme apresentado nas Tabelas 1 e 2 . O vento sinótico manteve-se soprando de norte entre os períodos de 28 a 31 de maio e 02 a 05 de junho de 2005 ,
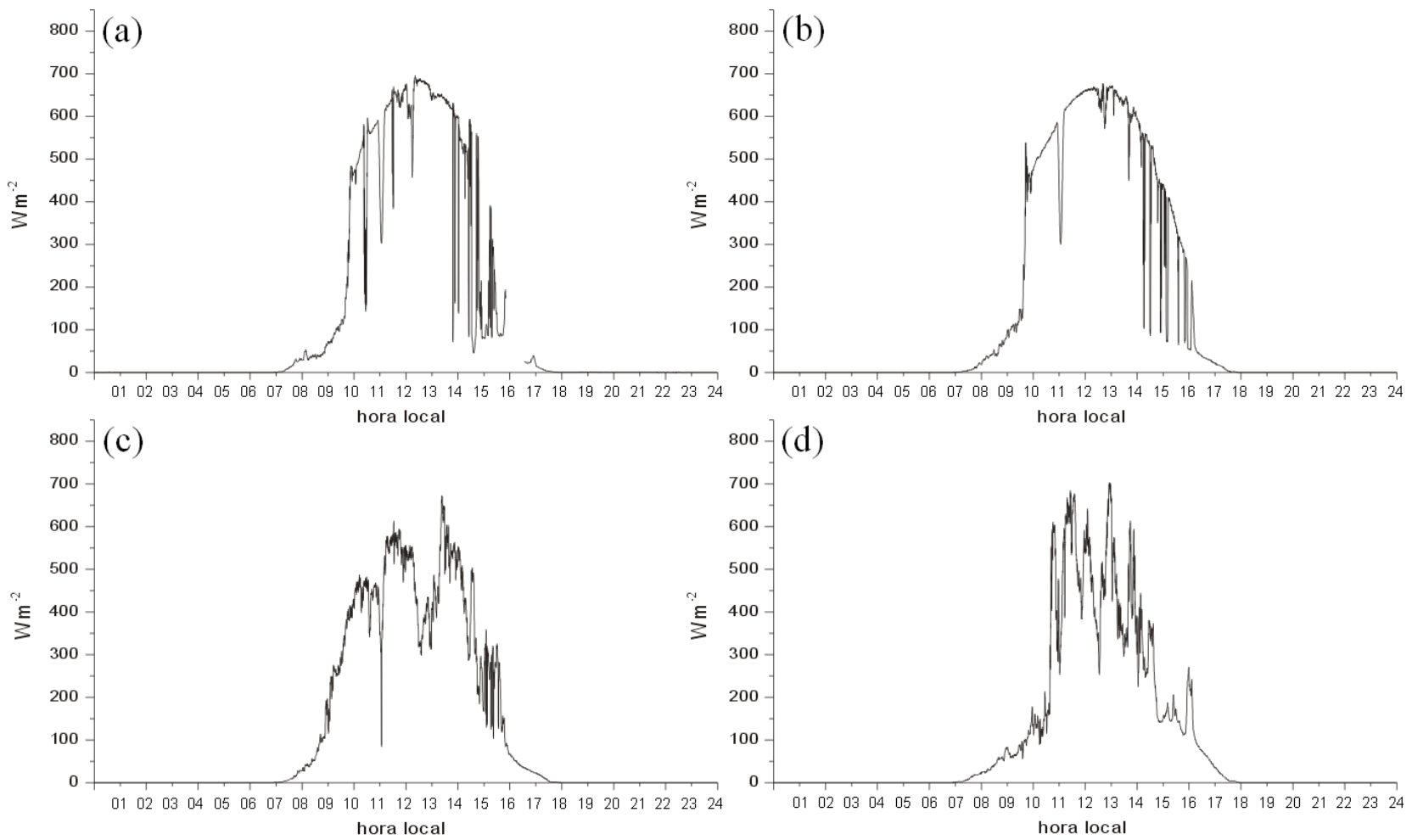

Figura 7 - Radiação solar incidente observada no vale do rio da Prata nos dias (a) 02, (b) 03, (c) 04 e (d) 05 de junho de 2005. 
com velocidades variando de 1 a $5 \mathrm{~m} \mathrm{~s}^{-1}$. Foi registrado calmaria somente nos dias 30 e 31 de maio e no dia 05 de junho.

Entre os dias 28 e 31 de maio (Figura 8) e entre os dias 02 e 05 de junho de 2005 (Figura 9), o vento local no fundo do vale do rio da Prata apresentou direção predominante ao longo do vale, fluindo na maior parte do tempo entre as direções oeste para leste $\left(270^{\circ}\right)$ e noroeste para sudeste $\left(315^{\circ}\right)$. Em quase todos os dias estudados, percebe-se muito claramente uma significativa influência da diferenciação térmica da superfície sobre o sentido da circulação, favorecendo vento local vale abaixo (oeste para leste) durante a madrugada e em parte do período da manhã, quando muitas vezes mantém-se formada uma forte camada de nevoeiro, e vento local mais fraco e menos freqüente no sentido vale acima (leste para oeste) durante os horários diurnos. Em quase todos os dias analisados, o vento local é muito calmo ou inexistente após as 12 ou $13 \mathrm{~h}$. Essa situação pode ser devido ao vento local vale acima, provocado pela diferenciação térmica, ter magnitude próxima ao vento local vale abaixo que é provocado pela canalização do vento sinótico.

Avaliando somente a primeira seqüência de dias (Figura 8), nota-se que a velocidade do vento local raramente ultrapassou $1 \mathrm{~m} \mathrm{~s}^{-1}$. Entretanto, comparando todos os momentos do dia, o

Tabela 1 - Direção e velocidade do vento sinótico observado nas estações de superfície entre 28 e 31 de maio de 2005 , em três horários sinóticos $(00,12$ e $18 \mathrm{TMG})$. h é a hora local.

\begin{tabular}{|c|c|c|c|c|c|c|c|c|c|c|c|c|c|}
\hline \multirow{2}{*}{ Estação } & \multirow{2}{*}{ Variável } & \multicolumn{3}{|c|}{$28 / 05$} & \multicolumn{3}{|c|}{$29 / 05$} & \multicolumn{3}{|c|}{$30 / 05$} & \multicolumn{3}{|c|}{$31 / 05$} \\
\hline & & 09h & $15 \mathrm{~h}$ & $21 \mathrm{~h}$ & 09h & $15 \mathrm{~h}$ & $21 \mathrm{~h}$ & 09h & $15 \mathrm{~h}$ & $21 \mathrm{~h}$ & 09h & $15 \mathrm{~h}$ & $21 \mathrm{~h}$ \\
\hline Lagoa & $\operatorname{dir}\left({ }^{\circ}\right)$ & 05 & 05 & 05 & 05 & 32 & 05 & 05 & 05 & -- & 05 & 32 & 09 \\
\hline Vermelha & vel $\left(m^{-1}\right)$ & 03 & 03 & 03 & 03 & 03 & 01 & 01 & 01 & 00 & 03 & 03 & 03 \\
\hline Bento & $\operatorname{dir}\left(\left(^{\circ}\right)\right.$ & 36 & 05 & 05 & 05 & 32 & 36 & 05 & 05 & 09 & 05 & -- & 05 \\
\hline Gonçalves & $\operatorname{vel}\left(\mathrm{ms}^{-1}\right)$ & 03 & 02 & 05 & 04 & 03 & 01 & 02 & 01 & 01 & 03 & 00 & 01 \\
\hline Caxias do & $\operatorname{dir}\left({ }^{\circ}\right)$ & 32 & 32 & 36 & 36 & 36 & 36 & -- & 32 & 05 & 36 & 36 & 32 \\
\hline Sul & $\operatorname{vel}\left(\mathrm{ms}^{-1}\right)$ & 01 & 01 & 01 & 05 & 05 & 01 & 00 & 01 & 01 & 03 & 01 & 01 \\
\hline
\end{tabular}

(a)

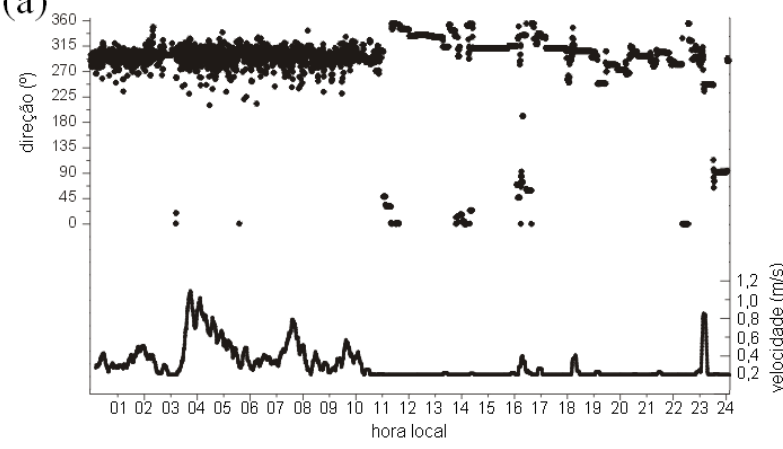

(c)

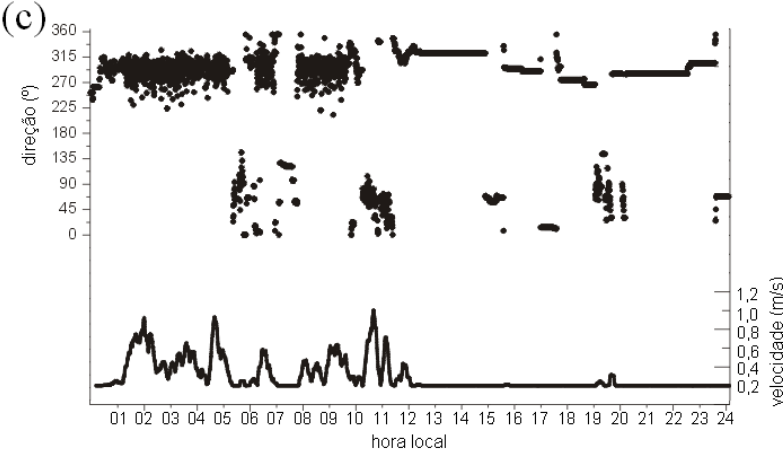

(b)

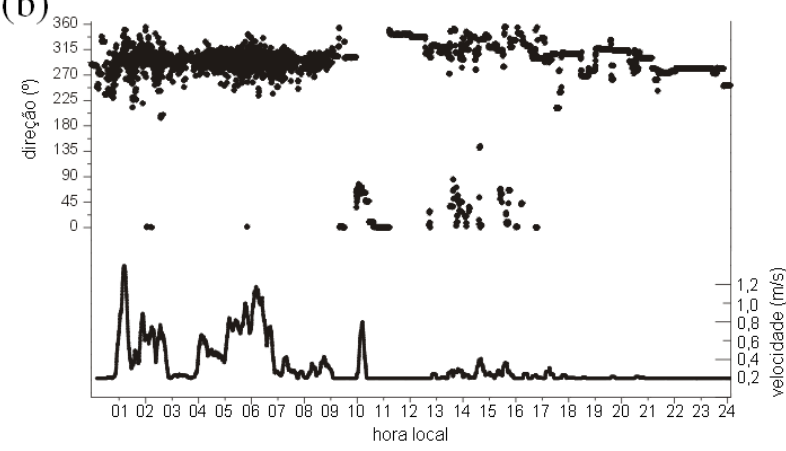

(d)

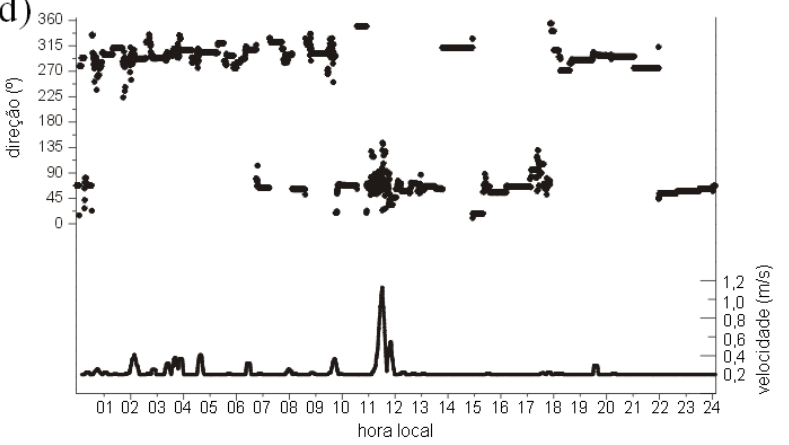

Figura 8 - Direção e velocidade do vento local observado no fundo do vale nos dias (a) 28, (b) 29, (c) 30 e (d) 31 de maio de 2005. 
vento local esteve mais intenso entre $00 \mathrm{~h}$ até próximo das $12 \mathrm{~h}$, nos dias 28, 29 e 30 de maio (Figura 8a-c). Supõe-se que esse comportamento de vento local esteja associado a superposição das forçantes térmica e canalizada sugerida por Bitencourt e Acevedo (2006). As temperaturas mínimas no interior do vale, nas madrugadas dos dias 28, 29 e 30 de maio, foram em torno de 10,12 e $13{ }^{\circ} \mathrm{C}$, respectivamente. Durante a noite e em boa parte da manhã, o vento local fluiu vale abaixo por causa desses valores baixos de temperatura que tornou o ar mais denso, mas também houve contribuição do vento sinótico canalizado através do trecho norte/sul, que antecede o trecho leste/oeste em estudo. Somente entre as 10 e $12 \mathrm{~h}$ do dia 30 de maio (Figura 8c) o vento local fluiu de leste para oeste, com velocidade entre 0,5 e $1 \mathrm{~m} \mathrm{~s}^{-1}$. No dia 31 de maio o vento sinótico manteve-se com a mesma direção e velocidade dos dias anteriores (Tabela 1), mas devido a aproximação do sistema frontal a nebulosidade foi bem maior na região de NRS. Essa situação proporcionou menor perda radiativa, com menor declínio de temperatura

Tabela 2 - Velocidade e direção do vento sinótico observado nas estações de superfície entre 02 e 05 de junho de 2005 , em três horários sinóticos (00, 12 e 18 TMG). h é a hora local.

\begin{tabular}{|c|c|c|c|c|c|c|c|c|c|c|c|c|c|}
\hline \multirow{2}{*}{ Estação } & \multirow{2}{*}{ Variável } & \multicolumn{3}{|c|}{$02 / 06$} & \multicolumn{3}{|c|}{ 03/06 } & \multicolumn{3}{|c|}{$04 / 06$} & \multicolumn{3}{|c|}{$05 / 06$} \\
\hline & & 09h & $15 h$ & $21 \mathrm{~h}$ & 09h & $15 h$ & $21 \mathrm{~h}$ & 09h & $15 \mathrm{~h}$ & $21 \mathrm{~h}$ & 09h & $15 \mathrm{~h}$ & $21 \mathrm{~h}$ \\
\hline Lagoa & $\operatorname{dir}\left({ }^{\circ}\right)$ & 05 & 05 & 05 & 05 & 32 & 05 & 05 & 32 & 14 & 05 & 32 & --- \\
\hline Vermelha & $\operatorname{vel}\left(\mathrm{ms}^{-1}\right)$ & 03 & 03 & 03 & 03 & 03 & 01 & 03 & 03 & 01 & 03 & 03 & 00 \\
\hline Bento & $\operatorname{dir}\left(\left(^{\circ}\right)\right.$ & 05 & 36 & 05 & 05 & 36 & 05 & 36 & 32 & 05 & 36 & 32 & 05 \\
\hline Goncalves & $\operatorname{vel}\left(\mathrm{ms}^{-1}\right)$ & 02 & 03 & 02 & 02 & 01 & 01 & 02 & 02 & 02 & 03 & 01 & 01 \\
\hline Caxias do & $\operatorname{dir}\left({ }^{\circ}\right)$ & 36 & 36 & 36 & 36 & 32 & 36 & 32 & 32 & 36 & 36 & 32 & -- \\
\hline & $\operatorname{vel}\left(\mathrm{ms}^{-1}\right)$ & 03 & 03 & 01 & 05 & 01 & 01 & 05 & 03 & 01 & 01 & 03 & 00 \\
\hline
\end{tabular}

(a)

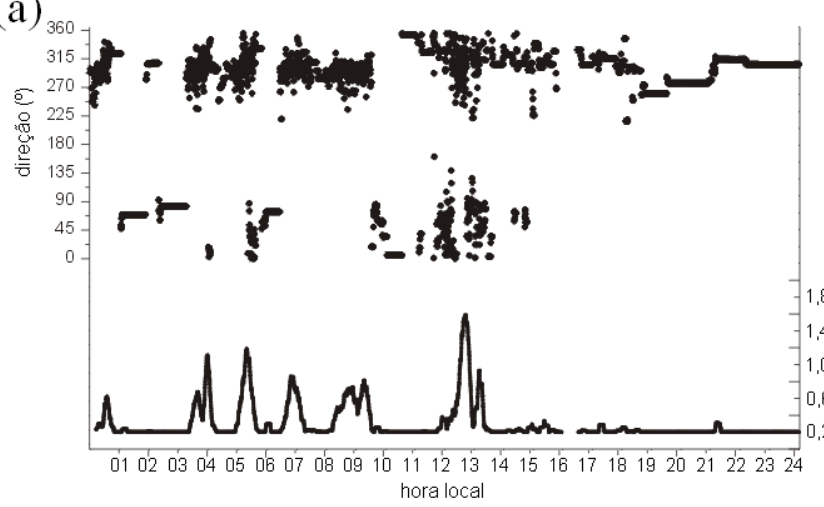

(c)

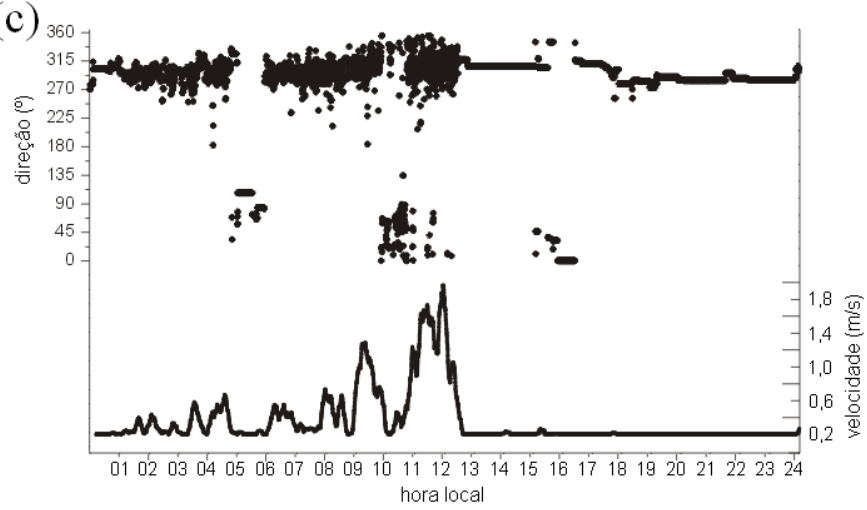

(b)

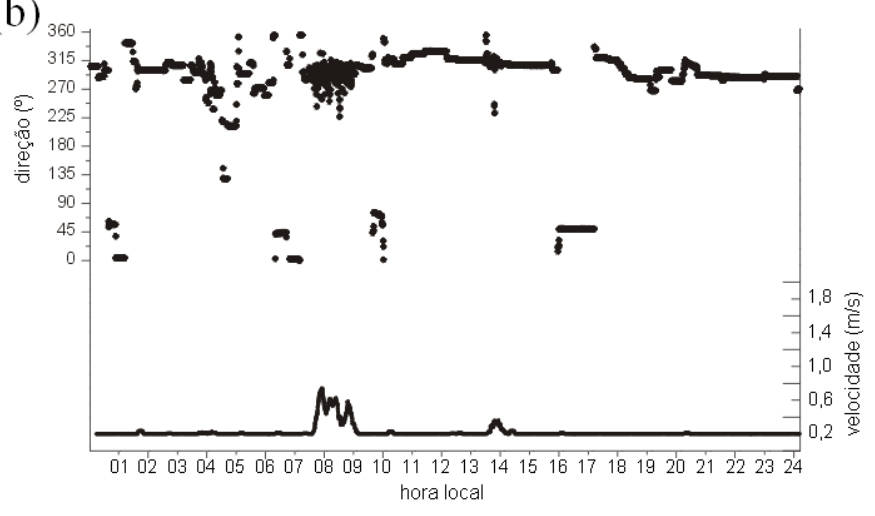

(d)

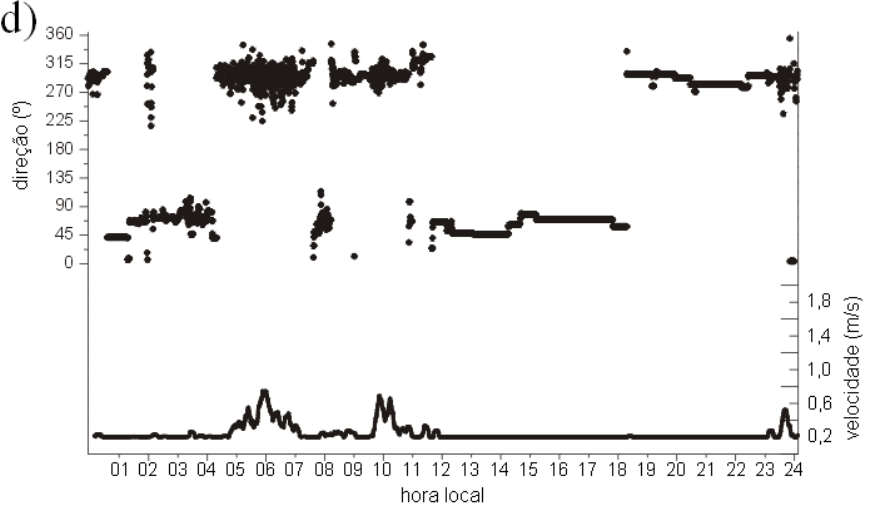

Figura 9 - Direção e velocidade do vento local observado no fundo do vale nos dias (a) 02, (b) 03, (c) 04 e (d) 05 de junho de 2005. 
durante a madrugada. A temperatura mínima registrada foi maior que nos dias anteriores, aproximadamente $15^{\circ} \mathrm{C}$, favorecendo a diminuição da forçante térmica. Ao mesmo tempo, durante a madrugada, foi mantida a canalização do vento sinótico e o escoamento do vento local ocorreu vale abaixo, mas com menor velocidade (Figura 8d) em relação aos dias anteriores.

$\mathrm{O}$ vento sinótico manteve-se de norte com velocidade de 1 a $5 \mathrm{~m} \mathrm{~s}^{-1}$ entre os dias 02 e 05 de junho (Tabela 2). Desse período, os dias 03 e 05 de junho (Figura 9b e 9d) apresentaram situação similar ao dia 31 de maio (Figura 8d). Apesar de não ter sido registrado presença de nebulosidade na região de NRS, a temperatura do ar durante a madrugada no interior do vale ficou entre 15 e $16^{\circ} \mathrm{C}$, amenizando o efeito térmico e diminuindo a velocidade do vento local. Essa situação indica que o vento sinótico foi uma importante forçante responsável pelo vento local vale abaixo, resultando em baixas velocidades do vento local de oeste. Entretanto, isso não explica o comportamento do vento local nos dias 02 e 04 de junho que, da mesma forma que os dias 03 e 05 de junho, registraram temperatura mínima entre 15 e $16^{\circ} \mathrm{C}$ na madrugada e temperatura máxima em torno de $24{ }^{\circ} \mathrm{C}$ à tarde. Nos dias 02 e 04 de junho a velocidade do vento local no fundo do vale foi maior nos horários próximos ao meio dia (Figura 9a e 9c), sugerindo que o efeito térmico foi mais importante, sobrepondo com maior facilidade o padrão de vento local de oeste proporcionado pelo efeito canalizado. Com isso, supõe-se que, dependendo da situação, outros efeitos, além das forçantes térmica e canalizada, são importantes para o comportamento do vento local no fundo do vale do rio da Prata. Com resultados de um trabalho de estudo de caso, Whiteman (1982) apresentou uma estrutura de circulação específica para o período de quebra da inversão térmica, em que os ventos noturnos vale abaixo continuam presentes, após o nascer do sol, através de uma região ainda estável no interior do vale. No vale do rio da Prata, essa estabilidade é bastante evidente durante boa parte da manhã, visto a observação de forte nevoeiro que muitas vezes dissipa pouco antes do meio dia. Entretanto, em alguns dias a dissipação do nevoeiro ocorre bem antes, fato que pode interromper o vento local de oeste (vale abaixo) já no início da manhã e inverter o sentido, passando a soprar de leste (vale acima). Essa antecipação da inversão do padrão de vento local de oeste, em contraposição ao vento sinótico canalizado, pode ter sido a causa da velocidade do vento local nos dias 02 e 04 de maio ser maior do que nos dias 03 e 05 de maio.

\section{CONCLUSÕES}

Nos dois estudos de caso analisados nesse trabalho o vento sinótico manteve-se com o mesmo padrão de velocidade e direção em NRS, predominando sempre do quadrante norte. Constataram-se três processos importantes a partir dos resultados encontrados na avaliação empírica do vento local no interior do vale do rio da Prata. O primeiro deles é a possibilidade do vento sinótico canalizar através do trecho norte/sul, que antecede o trecho leste/oeste do vale em estudo. O segundo processo diz respeito à superposição das forçantes térmica e canalizada como responsáveis pelas maiores velocidades do vento local durante a madrugada e parte da manhã. Entre a tarde e início da noite, quando os efeitos térmico e canalizado são contrários, o vento local é nulo ou muito fraco. O terceiro processo está relacionado à existência de outros fatores, tais como o nevoeiro, que dependendo da situação, apresenta-se também com bastante importância para o vento local.

Pelo menos com as condições meteorológicas de escala sinótica atuantes nos dias estudados, durante a madrugada e parte da manhã sempre ocorre superposição das forçantes térmica e canalizada no interior do vale do rio da Prata. Entretanto, a forçante térmica apresentou-se mais determinante nos casos em que a temperatura mínima do ar, registrada durante a madrugada no interior do vale, foi inferior a $14^{\circ} \mathrm{C}$. Quando a temperatura mínima ficou entre 15 e $16^{\circ} \mathrm{C}$, o efeito térmico pareceu não ser tão pronunciado, porém ainda notou-se a existência de vento local vale abaixo durante a madrugada e em parte da manhã, provavelmente devido ao efeito canalizado. Alguns dias com mesmo padrão sinótico e valores similares de temperatura no interior do vale mostraram discrepâncias na direção e velocidade do vento local, possivelmente devido a antecipações do horário de dissipação do nevoeiro. Além disso, a dissipação diferencial do nevoeiro ao longo do vale pode ser responsável por mudanças contínuas de sentido do vento local.

Os estudos de caso apresentados nesse trabalho aprimoraram os conhecimentos sobre a conduta do vento local no fundo do vale do rio da Prata, além de terem ratificado a hipótese da existência de superposição das forçantes térmica e canalizada no interior desse vale. Entretanto, esses resultados foram obtidos a partir de hipóteses com base em dados observados em um único ponto do trecho leste/oeste do vale do rio da Prata e em apenas dois estudos de caso. Por isso, ressaltase sobre a importância de maiores investigações, especialmente através de avaliações no interior do vale sob diferentes condições meteorológicas de escala sinótica. Além disso, a quantificação do efeito térmico poderá ser melhor identificada com um número maior de medidas ao longo do vale.

\section{AGRADECIMENTOS}

Agradecemos a Vagner Anabor, Hans Zimermann, Roberto Magnago e Rodrido Silva, pelas atividades desenvolvidas no trabalho de campo em NRS, fundamentais à obtenção dos dados utilizados nesse artigo. 


\section{REFERÊNCIAS BIBLIOGRÁFICAS}

ACEVEDO, O. C.; FITZJARRALD, D. R.. The Early Evening Surface-Layer Transition: Temporal and Spatial Variability.

J. Atmos. Sci., v. 58, n. 17, p.2650-2667, 2001.

ACEVEDO, O. C.; MORAES, O. L. L.; DEGRAZIA, G. A.; ANABOR, V.; SILVA, R.; BITENCOURT, D. P.; ZIMERMANN, H. R.; MAGNAGO, R. O.; PUHALES, F. S.; PABLO, E. S. O.. EXPANTAS 2005: Experimento de Observações das Transferências entre a Superfície e a Atmosfera na Região do Rio das Antas. Ciência e Natura, Santa Maria, RS, v. esp., p.209-212, 2005.

ACEVEDO, O. C.; MORAES, O. L. L.; SILVA, R.; ANABOR, V.; BITENCOURT, D. P.; ZIMERMANN, H. R.; MAGNAGO, R. O.; DEGRAZIA, G. A. Surface to atmosphere exchange in a River Valley environment. J. Appl. Meteor., v. 46, p. 1169-1181, 2007.

BADER, D. C.; MCKEE, T. B.. Dynamical Model Simulation of the Morning Boundary Layer Development in Deep Mountain Valleys. J.Atmos. Sci., v. 22, n. 3, p.341-351, 1983.

BANTA, R. M.. Daytime Boundary-Layer Evolution over Mountainous Terrain. Part 1: Observations of the Dry Circulations. Mon. Wea. Rev., Ft. Collins, v. 112, n. 2, p.340-356, 1984.

BITENCOURT, D. P.; ACEVEDO, O. C.. Conexão da circulação de grande escala com o vento local e os fluxos na superfície de um vale. In: Congresso Brasileiro de Meteorologia 14, 2006, Florianópolis, Anais ... em CD-ROM, 2006.

BITENCOURT, D. P.; ACEVEDO, O. C.. Modelling the Interaction Between a River Surface and the Atmosphere at the Bottom of a Valley. Boundary-Layer Meteorology, v. 129, p.309-321, 2008.

COTTON, W. R.; GEORGE, R. L.; KNUPP, K. R.. An Intense, Quasi-Steady Thunderstorm over Mountainous Terrain. Part I: Evolution of the Storm-Initiating Mesoscale Circulation.

J. Atmos. Sci., v. 39, n. 2, p.328-342, 1982.

DEFANT, F. Local Winds. In: COMPENDIUM OF METEOROLOGY (T. F. Malone, Ed.), Amer. Meteor. Soc., p.655-672, Boston, 1951.

DORAN, J. C.; HORST, T. W.. Velocity and Temperature Oscillations in Drainage Winds. J. Appl. Meteor., Richland, p.361-364, 1981.
FITZJARRALD, D. R.; LALA, G. G.. Hudson Valley Fog Environments. J. Appl. Meteor., v. 28, n. 12, p.1303-1328, 1989.

KALNAY, E.; KANAMITSU, M.; KISTLER, R.; COLLINS, W.; DEAVEN, D.; GANDIN, L.; IREDELL, M.; SAHA, S.; WHITE, G.; WOOLLEN, J.; ZHU, Y.; CHELLIAH, M.; EBISUZAKI, W.; HIGGINS, W.; JANOWIAK, J.; MO, K. C.; ROPELEWSKI, C.; WANG, J.; LEETMAA, A.; REYNOLDS, R.; JENNE, R.; JOSEPH, D.. The NCEP/ NCAR 40-Year Reanalysis Project. Bull. Am. Meteorol. Soc., v. 77, n. 3, p. 437-471, 1996

PILIÉ, R. J.; MACK, E. J.; KOCMOND, W. C.; ROGERS, C. W.; EADIE, W. J.. The Life Cycle of Valley Fog. Part I: Micrometeorological Characteristics. J. Appl. Meteor., v. 14, n. 3, p.347-363, 1975.

SEGAL, M.; MAHRER, Y.; PIELKE, R. A.. A study of meteorological patterns associated with a lake confined by mountains - the Dead Sea case. Quart. J. Roy. Meteor. Soc., v. 109, n. 461, p.549-564, 1983.

WEIGEL, A. P.; ROTACH, M. W.. Flow structure and turbulence characteristics of the daytime atmosphere in a steep and narrow Alpine valley. Quart. J. Roy. Meteor. Soc., v. 130, n. 602, p.2605-2627, 2004.

WHITEMAN, C. D.. Breakup of Temperature Inversions in Deep Mountain Valleys: Part I. Observations. J. Appl. Meteor., Richland, v. 21, n. 3, p.270-289, 1982.

WHITEMAN, C. D.; DORAN, J. C.. The Relationship between Overlying Synoptic-Scale Flows and Winds within a Valley. J. Appl. Meteor., Richland, v. 32, n. 11, p.1669-1682, 1993.

WHITEMAN, C. D.; MCKEE, T. B.. Breakup of Temperature Inversions in Deep Mountain Valleys: Part II. Thermodynamic Model. J. Appl. Meteor., Richland, v. 21, n. 3, p.290-302, 1982.

WHITEMAN, C. D.; BIAN, X.; SUTHERLAND, J. L.. Wintertime Surface Wind Patterns in the Colorado River Valley. J. Appl. Meteor., v. 38, n. 8, p.1118-1130, 1999. 